\title{
AS CIDADES SEM CIDADANIA: A PERCEPÇÃO DO SUJEITO PERANTE O ESPAÇO PÚBLICO DESAPROPRIADO DA COLETIVIDADE'
}

\author{
Rogério Rodrigues iD 1
}

Resumo: Este artigo tem como objetivo definir o conceito da percepção como o sujeito representa para si o espaço público numa perspectiva crítica. Este estudo parte da hipótese que a modernidade produz cidades em que o sujeito se encontra desapropriado do território, em espaços antagônicos para o exercício da cidadania. A nossa metodologia se encontra no campo da Filosofia da Educação na perspectiva da hermenêutica, na qual se busca analisar os processos formativos como práticas sociais que determinam uma concepção de mundo em que os sujeitos perdem a sensibilidade perante a vida em cidade, desconstruindo sua cidadania. A principal conclusão do estudo é que a manutenção dos sujeitos na posição não pensante no modo de compreender coletivamente a vida nas cidades decorre da regressão dos espaços coletivos que possam proporcionar-lhe a experiência vivida ao encontrar alguns pontos de fuga do modelo de sociedade alienante.

Palavras-chave: Cidade; Cidadania; Urbanismo; Educação; Emancipação.

\section{THE CITIES WITHOUT CITIZENSHIP: THE PERCEPTION OF THE SUBJECT BEFORE THE PUBLIC SPACE EXPROPRIATED OF THE COLLECTIVE}

\begin{abstract}
The objective of this article is to define the concept of perception as the subject represents the public space in a critical perspective. This study starts from the hypothesis that modernity produces cities in which the subject is expropriated of the territory, in spaces antagonistic for the exercise of citizenship. The methodology used is in the field of Philosophy of Education from the perspective of hermeneutics, which seeks to analyze the formative processes as social practices that determine a conception of the world in which subjects lose sensitivity to life in the city, deconstructing their citizenship. The main conclusion of the study is that the maintenance of the subjects in the non thinking position in the way of collectively understanding life in the cities is a result of the regression of the collective spaces that can give him the lived experience when finding some vanishing points of the model of alienating society.
\end{abstract}

Keywords: City; Citizenship; Urbanism; Education; Emancipation.

\section{A perda da cidadania e a vida na cidade como lugar do antagonismo do espaço público representado pelo individualismo}

${ }^{1}$ Doutor em Educação pela Universidade Estadual de Campinas (UNICAMP). Professor Titular da Universidade Federal de Itajubá (UNIFEI). E-mail: rrunifei@hotmail.com. 
As relações dos sujeitos na vida em cidade são mediadas pelas leis de convivência estabelecidas em comum acordo ou em aspectos jurídicos que instituem um conjunto de regras para o convívio de todos no espaço público, onde 0 bem comum prevalece aos interesses particulares. Portanto, na modernidade, sujeito que vive na cidade se subordina às regras comuns a todos, em detrimento da vontade particular, para que o resultado seja a harmonia no convívio no espaço público, sem a existência do confronto das particularidades, prevalecendo, assim, algo comum a todos.

Pode-se constatar que, no exercício cotidiano da cidadania, o que prevalece no espaço público é o conflito dos interesses particulares, que são mediados pelo permanente diálogo, no sentido de encontrar algo em comum a todos que participam da coletividade que se instaura na tão desgastada noção de democracia.

Nesta perspectiva, o espaço público torna-se antagônico ao conceito de cidadania, ao ser utilizado pelo sujeito que se subordina ao comum de todos, não podendo ser apropriado pelo interesse particular. Nessa dinâmica, a grande dificuldade seria estabelecer uma relação de uso e pertencimento, mas sem a condição de apropriação como propriedade particular. Isso significa reconhecer que aquilo que é público pertence a todos e deve ser cuidado por cada um que Ihe utiliza. Para tanto, a experiência de vida na cidade deveria ser a construção da noção de pertencimento de algo comum que seja de todos, e isso se constitui numa determinada representação e percepção do sujeito perante os diversos lugares apropriados pela coletividade.

A partir da perspectiva crítica, a existência do sujeito no dia a dia da cidade seria a busca de inserção na vida urbana, em oposição direta à noção de propriedade particular, na qual o espaço público é representado pela ideia de pertencimento não comum a todos. Portanto, o espaço público deveria ser representado por todos como algo sem o direito de propriedade particular e utilizado como um bem comum a todos que se encontra para além do interesse particular do sujeito.

Nessa dinâmica, na compreensão da disputa pelo espaço entre o pertencimento comum e o uso particular, estaria presente o elemento básico para a condição da construção da cidadania. Em oposição a essa situação, a cidade sem cidadania seria a condição na qual se instaura a hegemonia da concepção do particular, que se estabelece no apagamento da discórdia e na completa unanimidade pautada no dogma de que o interesse comum a todos deve ficar subordinado ao interesse particular ou de um grupo qualquer que se apropria do espaço público.

A apropriação do espaço comum como uso particular se impõe nas articulações de forças físicas de domínio ou nas artimanhas do controle, em que se estabelece o mascaramento da verdade de que o comum a todos ao se encontrar alinhado ao interesse particular. Essa subordinação se apresenta como algo natural uma vez que os sujeitos se em constituem na obediência dos "corpos dóceis" em favorecimento da hegemonia (FOUCAULT, 1991), que seria, 
corpo - ao corpo que se manipula, se modela, se treina, que obedece, responde, se torna hábil ou cujas forças se multiplicam. O grande livro do Homem-máquina foi escrito simultaneamente em dois registros: no anátomo-metafísico, cujas primeiras páginas haviam sido escritas por Descartes e que os médicos, os filósofos continuaram; o outro, técnicopolítico, constituído por um conjunto de regulamentos militares, escolares, hospitalares e por processos empíricos e refletidos para controlar ou corrigir as operações do corpo (FOUCAULT, 1991, p. 125-6).

Nesse caso, seria relevante lembrar aqueles que desejam a ruptura com a hegemonia constituída o aforismo de Nietzsche: os "Inimigos da verdade convicções são inimigos da verdade mais perigosos que as mentiras" (NIETZSCHE, 2000, p. 265).

Compreender isso na radicalidade seria a condição de o Estado atuar na situação de fiscalizar as implementações de concessões de exploração do espaço público pela iniciativa particular, pautado na convicção de que essas parcerias entre o público e o privado sejam um benefício para o bem comum. Essa necessidade do Estado fiscalizador ocorre no princípio de que o comum a todos é um patrimônio e, portanto, compete à prestação de contas de que este está sendo utilizado no termo da concessão no gerenciamento da empresa particular. Portanto, somente com a atuação de órgãos fiscalizadores que façam valer as causas contratuais é que se permite estabelecer as condições necessárias dos benefícios para todos em relação à ocupação do espaço público.

Neste contexto em que o espaço público deixa de ser um bem com a todos, torna-se um verdadeiro paradoxo quando o próprio Estado autoriza a concessão, permitindo que espaços comuns a todos se fechem para uso particular, por exemplo, a restrição de entrada dos sujeitos nas ruas sem saídas, em que se colocam grades e portões, fazendo criar condomínios fechados em espaços de circulação pública.

O ponto a ser analisado é que a discórdia do fechamento do espaço público seria a experiência democrática que se apresenta no conflito como resultado do exercício da cidadania e, principalmente, na manutenção da tolerância que se produz na expressão permanente das divergências. Esse elemento é que se deveria observar em diversas ações difusas, que podem se apresentar como reivindicação referente ao uso dos espaços públicos da cidade (MENDONÇA, 2021).

A perda da cidadania seria a inversão da lógica da subordinação do particular ao comum, em que a participação requer um permanente diálogo de pertencimento no coletivo. Essa situação requer o saber lidar com o conflito do interesse particular que se dissolve na vontade do grupo que utiliza o referido espaço público. Aqui, a presença do Estado como elemento mediador torna-se pertinente na gestão do espaço público como algo de interesse comum a todos. Na identificação do sujeito de que os espaços das cidades é algo da ordem do pertencimento comum a todos é que se torna presente o exercício da cidadania.

O inverso dessa situação se constitui no não reconhecimento do espaço como um lugar comum a todos e que se representa numa cidade sem 
cidadania. Isso seria a recusa do diálogo entre os sujeitos em que a condição do comum ficar reduzida aos interesses do particular, prevalecendo o confronto, numa apropriação indevida daquilo que seria o espaço público, o que geralmente se instaura pelas leis do mercado ou a lei da força física.

Essa condição do particular que se impõe como regra de vida nas cidades prevalece como instauração da anulação do contraditório, no sentido de implementar a existência de uma cidade sem cidadania, em que as possibilidades de interpretar suas leis ficam reduzidas aos traços da ausência do diálogo, privatizando o espaço público em seu uso de modo particular.

A perda de cidadania nos espaços das cidades também ocorre em decorrência da precarização do sujeito no campo da cultura, em que a representação do espaço público como algo comum a todos se anula na falta de compreensão do que seria o bem comum. Essa condição de embrutecimento do sujeito perante a ocupação do espaço comum a todos se torna algo concebido como normal, em que se identificam os espaços comuns a todos como lugares que possuem dono, como aquele que manda e determina suas regras de uso.

O que assistimos de modo geral nas cidades são os diversos espaços públicos e privados que se encontram vigiados por câmeras e fechados por grades e muros, para restringir e controlar o acesso dos sujeitos. As vias públicas passam a fazer parte de lugares de passagem, sem qualquer reconhecimento de pertencimento com o lugar. Portanto, os sujeitos se deslocam pelas cidades numa lógica do não pertencimento uma vez que não ocorrem interações com o espaço local e com as pessoas, pois:

Obviamente, as relações entre os corpos humanos no espaço é que determinam suas reações mútuas, como se veem e se ouvem, como se tocam ou se distanciam. [...] Hoje em dia, viaja-se com uma rapidez que nossos ancestrais sequer poderiam conceber. A tecnologia da locomoção - dos automóveis às grandes rodovias - permitiu que as pessoas se deslocassem para áreas além da periferia (SENNETT, 1997, p. 17).

Essa falta de pertencimento com o espaço público, de um lado, amplia a possibilidade de este ser controlado pela ilegitimidade, o que 0 torna propriedade de verdadeiras gangues, que se afirmam pela força como proprietárias dos espaços públicos, e o simples fato de se estacionar o automóvel passam a ser tarifado por um comércio paralelo às leis da cidade. $A$ constatação empírica desse fato é muito simples, pois basta uma aproximação a lugares de confluência de diversos sujeitos, para que se perceba que o espaço público se encontra locado por aqueles que se apresentam como donos.

Por outro lado, a legalidade do uso do espaço público determina as possíveis formas de expressões em diversas outras linguagens, que podem ocorrer somente com a autorização do poder público ou privado. Nessa interface entre o público e o privado, o paradoxo se torna caso de direito ao acesso. Temos instaurado, no Brasil, diversos condomínios fechados que impedem o acesso à praia como um lugar de bem comum a todos. O exemplo mais bizarro dessa situação se encontra no Quilômetro Dezessete, na estrada Guarujá e Bertioga, em que a entrada para o acesso à praia é controlado por 
um condomínio particular. Pode-se entrar no referido espaço apenas um número determinado de automóveis. Quando o estacionamento do condomínio reservado para os "visitantes" fica cheio, não se pode entrar mais nenhum automóvel. O próximo automóvel pode entrar somente quando alguém sai do condomínio na condição de "visitante". Em épocas de alta temporada no verão, formam-se longas filas de automóveis na beira da estrada, à espera de que alguém que saia do condomínio para poder entrar na referida praia. No mesmo condomínio, a guarita de entrada tem duas passagens. Uma destinada aos proprietários de casas, que nunca tem fila para entrar, e outra destinada aos "visitantes", na qual se forma uma longa fila de espera. Essa divisão caracteriza algo muito peculiar: não somos todos iguais perante a lei, quando os espaços públicos, como no caso da praia, têm dono e que, no máximo, o acesso do cidadão comum é regido por regras que não fazem parte do conceito de cidadania.

Temos como pressuposto que essas duas faces do uso do espaço público (ilegitimidade e legalidade) o tornam um lugar desastroso, permeado pela interdição e restrição do uso particular, numa ordenação pautada pelas violências física e simbólica, que se estabelecem em diversos níveis de situações, que vão desde regras sem nexo até o ponto de ameaças que permeiam a violência física, quando observamos que os espaços das cidades interditam a circulação dos sujeitos pelo medo. São elementos banais da vida cotidiana que apontam coisas que percebemos que não somos livres para ir e vir na condição do direito constitucional do Artigo $5^{\circ}$, no inciso XV, na garantia de "[...] livre a locomoção no território nacional em tempo de paz" (BRASIL, 2018b).

O espanto em relação a essa condição é que a instauração da barbárie na apropriação do comum a todos pelo interesse particular se torna a lei comum da rua, em oposição à lei da sociedade, que é obedecida por aqueles que se harmonizam com a violência difusa no todo social. São diversas as situações em que a presença do Estado não ocorre de modo efetivo, como por exemplo, ao buscar uma via alternativa para o trânsito e pedir informação para o sujeito que ali se encontrava presente, o mesmo profere as seguintes palavras: "moço, sai daqui que você vai ser assaltado!". Em outra ocasião ao pedir informação para encontrar um supermercado em bairro periférico, a explicação do sujeito é: "Olha o caminho é esse, mas tome muito cuidado para não errar!".

Aqueles que desobedecem à lei da rua são compreendidos como ingênuos, por não possuírem a malícia de querer entender que a lei que impera são outras formas de acordos para o convívio estabelecido na relação de força. O que ocorre nessas práticas instituídas é a perda da cidadania na vida na cidade, sendo esta o lugar do paradoxo do espaço público, representado pelo individualismo. Aqui se encontra um grande distanciamento entre o instituído na legalidade como prática social e a ilegitimidade para o convívio no espaço comum, o que muito se distancia da legitimidade, que se encontra rompida e estabelecida pelo cinismo perante as leis da cidade.

Tudo parece indicar que ocorre uma ilusão de que a escola seria outro espaço público que preparasse para a cidadania, com o exercício da lei da 
escola, entendida numa esfera para além da legalidade e na recusa da ilegitimidade, que seria a condição de requerer a legitimidade da vida em sociedade, uma vez que se podem compreender os espaços das cidades como lugares de encontro e discussão sobre as coisas comuns a todos. A legalidade da cidadania pode ser estabelecida como princípio educativo, uma vez que, na Lei de Diretrizes e Bases da Educação promulgada em 1996, afirma-se que

Art. $2^{\circ}$ A educação, dever da família e do Estado, inspirada nos princípios de liberdade e nos ideais de solidariedade humana, tem por finalidade 0 pleno desenvolvimento do educando, seu preparo para o exercício da cidadania e sua qualificação para o trabalho. (BRASIL, 2018a).

A construção da cidadania como elemento de legitimidade no processo formativo deveria ser também compreendida na escola como um lugar do exercício do conflito e ampliação da tolerância perante a diferença no preparo do sujeito para o encontro do outro na vida comum a todos. Portanto, o espaço escolar se apresenta como uma verdadeira praça pública, em que se pode fazer a experiência da vida num palco do conflito, em que o ato de escrever, ler e falar, na polis, representa-se quando se diz algo para todos os comuns. Neste contexto, a escola é um espaço em ocorre uma relação de pertencimento em que todos podem realizar

[...] a aventura da palavra se dá em num ato de ler em público. Em tais ocasiões, e especialmente quando esse ato de ler em público tem lugar uma sala de aula, costumamos dizer que se trata de uma lição. Lição, lectio, leitura. Uma lição é uma leitura e, ao mesmo tempo, uma convocação à leitura, uma chamada à leitura. Uma lição é a leitura e o comentário público de um texto cuja função é abrir o texto a leitura comum (LARROSA, 2004, p. 139).

Nas condições acima descritas, o conceito de cidadania está diretamente relacionado à representação de que espaço público deveria ser o lugar apropriado e privilegiado para fazer uso da palavra e falar para todos os presentes, na condição de suportar as divergências. Entretanto, em nossa vida na cidade, tudo indica que ocorre uma perda quase por completa da possibilidade de realização da lição como algo a ser realizado na construção da cidadania, como fazer uso da palavra no espaço público, seja numa escola, seja na praça.

As cidades se apresentam como "não-lugar" (AUGÉ, 1994), onde habita a ausência de representação do sujeito e, portanto, parecemos existir em lugares que não sejam a escola, a praça ou a cidade, e assim, tais lugares são habitados por não sujeitos, que se apresentam como verdadeiros seres sem representação e imagem de si e que se constituem "[...] de algum modo o instável umbral em que o homem passava a ser não-homem [...]" (AGAMBEN, 2008, 54-55).

O conceito de "não-lugar" se compreende como estar na cidade, mas sem reconhecer como sujeito de pertencimento no referido espaço, uma vez que "Se um lugar pode se definir como identitário, relacional e histórico, um 
espaço que não se definir nem como identitário, nem como relacional, nem como histórico definirá um não-lugar" (AUGÉ, 1994, p. 73).

Desse modo, podemos encontrar, como derivação do "não-lugar" (AUGÉ, 1994), a proposição de que temos também o não-sujeito como a instauração do não pertencimento a si mesmo como sujeito, em que "[...] a supermodernidade é produtora de não-lugares, isto é, de espaços que não são em si lugares antropológicos [...]" (AUGÉ, 1994, p. 73).

Essa concepção de não-lugar interage diretamente com aquele que não é sujeito e que se apresenta na radicalidade como não existente perante o social constituído. Aqui se apresenta o extremo daqueles que, ao invés de sobreviveram ao campo de concentração, apresentam-se como resto de algo que não se pode dizer o que é, pois se desfiguram da forma humana e se tornam como não-sujeitos, no paradoxo de mortos vivos.

Assim, podemos entender melhor esse "resto" como aquilo que, no testemunho, solapa a própria eficácia do dizer e, por isso mesmo, institui a verdade de sua fala; e, no tempo humano, como aquilo que solapa a linearidade infinita do chronos e institui a plenitude evanescente do tempo-de-agora como kairos messiânico (GAGNEBIA, 2008, p. 11).

Nessa lógica afirmativa de que vivemos em cidades que não reconhecemos como o nosso lugar, o referido espaço também se torna nãocidade, em que o comum em ser não-sujeito torna algo comum a todos a existência sem cidadania. Então ficar na fila e não poder entrar na praia, ter de voltar do caminho para não ser assaltado e tomar cuidado para não errar o caminho para ir ao supermercado fazem parte da narrativa de comum a todos que incorpora para si o conceito de existir sem cidadania.

Isso é o algo aparente, que se constitui no refúgio do sujeito, no sentido de organizar sua relação com o não-lugar (AUGÉ, 1994), espaço que ocupa em cidades que interditam ou alienam o ir e vir, numa passagem de lugar sem representação de pertencimento.

Os espaços sem sentido e a falta do tempo necessário para as tarefas da existência se constituem numa fórmula condizente, que impede o trabalho do pensamento crítico, no sentido de se permitir a elaboração do seu estado de não-sujeito (GAGNEBIA, 2008). Esse lugar do não-sujeito, que se produz como resultado, seria a condição de resto humano, numa condição de incompreensão por algo que não se pode elaborar pelo trabalho do pensamento e que, no caso do campo de extermínio dos prisioneiros, se

Perdiam tempo e energia em tentar compreender aquilo que thes acontecia, em querer entender que sistema regia o campo, em vez de se concentrar, desde o início, no único esforço válido, a saber: tentar sobreviver a qualquer custo, isto é, ao custo do entendimento e, também, da comunicação com os outros (GAGNEBIA, 2008, p. 9-10).

Esse esforço inválido para a compreensão do espaço público constitui-se num paradigma, no qual se difunde a modernidade como uma pós-verdade referente ao que seria o exercício da cidadania, já que habitamos lugares sem compreender suas demandas e entorno e, principalmente, as interdições que 
nos impedem de acessar os lugares públicos que deveriam ser plenamente representados como algo comum a todos, pautados na legitimidade.

Essa condição de ilegitimidade ou legalidade casual referente ao uso do espaço público constitui o mesmo no paradoxo de cidades com lugar da cidadania instrumental. Nesses lugares, ocorre o efeito da não representação das cidades, que são apenas utilizadas como espaços de circulação alienadas na condição do sujeito do ir e vir, dessa forma, os espaços públicos se constituem apenas como lugares de passagens, não fazendo parte do convívio do sujeito, nem podendo ocasionar uma experiência vivida.

Tudo parece indicar que o oposto da cidade instrumental seria a permanência do sujeito no lugar, estabelecendo algum sentido às cidades. Essa possibilidade da experiência de estar nas cidades é ter o tempo para pensar e, principalmente, em querer estar presente como sujeito cidadão em que se estabelece um elo de afetividade entre o lugar e o sujeito que se denomina a "topofílica" (TUAN, 1980).

Entretanto, na modernidade, as cidades se constituem primordialmente como lugares habitados por sujeitos que não possuem tempo e fazem do lugar um espaço de não-lugar (AUGÉ, 1994). Essa ausência de tempo e de pertencimento permite produzir a violência pública como efeito antagônico do não-sujeito, numa direta de não-lugar (AUGE, 1994).

Essa condição de não pertencimento nas cidades poderia talvez ser desconstruída como resultado de uma apropriação criativa dos espaços das cidades em que instaura o verdadeiro uso dos lugares como forma de bricolage (AGUIAR, 1989. p. 32), que, de um lado, as coisas se encaixam e produzem novos sentidos na execução de um trabalho qualquer, em que não há uma intencionalidade no modo de fazer as coisas. Portanto, a interação criativa do sujeito com os espaços públicos deveria tentar escapar dos projetos que normatizam o modo de ocupar para algo que seja a reinvenção do lugar.

Por outro lado, seus habitantes deveriam fazer um esforço em querer saber esses novos sentidos que nos fazem sujeitos pertencentes às cidades, na constituição de outro paradoxo da noção do não-pertencimento, que nos confunde na vida coletiva. Portanto, é preciso compreender o fenômeno do não pertencimento como o lugar como elemento fundamental importância em termos de reapropriação do conceito de cidadania, uma vez que, em cidades sem sentidos, buscam-se outros sentidos de representação, que são construídos no campo das significações referentes ao direito à cidade em que se instauram novos contornos de interpretação do espaço público.

Nesses outros sentidos de verdade, acerca da questão da cidadania, observa-se que a vida em multidão nas cidades nos torna sujeitos solitários, que em termos políticos se representa na constituição do sujeito que se aliena para se constituir na garantia política de encontrar algum significado para a vida na cidade, e isso se apresenta na perda da cidadania, no paradoxo da função política, pois a vida na cidade ocorre somente no antagonismo do espaço público, que se encontra representado pela predominância do individualismo (SENNETT, 1995). 


\title{
2. Cidadania e tecnologias: os processos formativos em interface com a vida nas cidades
}

Neste estudo, que se apresenta como ensaio pelo viés metodológico da hermenêutica se busca identificar o antagonismo nas relações dos sujeitos nos espaços públicos para o exercício da cidadania. Temos, então, como objetivo, definir o conceito de percepção do sujeito perante as cidades. Isso se justifica no sentido de compreender que a modernidade produz espaços de cidades em que o sujeito se situa desapropriado da coletividade e, simultaneamente, requisitado para exercício da cidadania. Essa condição tem produzido a compreensão do sentido conceitual da percepção dos espaços públicos no exercício da cidadania instrumental. Portanto, torna-se necessário evidenciar o paradoxo da constituição de cidades sem cidadania ou de cidade sem a representação da presença do sujeito, em que todo o urbano se constitui no entorno de concretos, muros e automóveis, resultando em sujeitos com perda de sensibilidade e que vivem em cidades sem a plena conexão com os espaços públicos. Nessa condição, transitar pela cidade apresenta-se como um fenômeno urbano e como instrumento de uso em que se constata a perda de relação com o lugar. Essa condição alienante do sujeito não se relacionar com lugar se amplia uma vez que:

\begin{abstract}
Atualmente, experimentamos uma facilidade de movimentação desconhecida de qualquer civilização urbana anterior à nossa, e, no entanto, a movimentação se tornou a atividade diária mais carregada de ansiedade. A ansiedade provém do fato de que consideramos a movimentação sem restrições do indivíduo como um direito absoluto. 0 automóvel particular é o instrumento lógico para o exercício desse direito, e o efeito que isso provoca no espaço público, especialmente no espaço da rua urbana, é que o espaço se torna sem sentido, até mesmo endoidecedor, a não ser que possa ser subordinado ao movimento livre. A tecnologia da movimentação moderna substitui o fato de estar na rua por um desejo de eliminar as coerções da geografia (SENNETT, 1995, p. 28).
\end{abstract}

Esse elemento do espaço público sem sentido se apresenta como um agravante político, pois a desapropriação ou a alienação da experiência de vida nas cidades reduz por completo qualquer possibilidade de cidade como lugar do convívio comum com o outro.

Diante desse fato, a nossa metodologia se encontra no campo da Filosofia da Educação, a partir da qual se busca analisar os processos formativos como práticas sociais que determinam uma concepção de mundo em que os sujeitos perdem a sensibilidade na vida em cidade e na desconstrução do espaço público como lugar do que é comum a todos. Essa condição instaura as cidades sem cidadania, pois constitui a percepção do sujeito perante o espaço público desapropriado da coletividade, há, portanto, o aniquilamento da cidadania.

Partimos da hipótese de que essa condição de aniquilamento da cidadania destitui a percepção do sujeito perante seu pertencimento ao espaço público, em que as cidades deixam de ser o lugar do encontro com o outro. 0 principal objetivo da análise desse fenômeno social seria estabelecer a 
compreensão sobre a vida dos sujeitos em cidades vazias de coletividade, uma vez que, na modernidade, ocorre uma predominância do projeto neoliberal, em que prevalece a concepção do individualismo, na apropriação territorial, e uma resistência na construção de espaços de coletividade no interior das cidades.

Podemos identificar que as cidades são constituídas como territórios individualizados, pautados no apoderamento autoritário e, principalmente, na instauração de espaços desterritorializados e destituídos do pensamento crítico, o que dificulta a troca de experiência vivida entre os sujeitos como processo de construção da cidadania. Nesse caso, o problema da pesquisa está no campo da Filosofia da Educação e dos processos formativos como práticas sociais que determinam uma concepção de mundo, na qual os sujeitos perdem a sensibilidade na vida em cidade, tendo sua cidadania desconstruída no paradoxo do pertencimento do que é comum a todos e do que não pertence a ninguém.

Tem-se, assim, um aprofundamento da hipótese de trabalho de que os sujeitos deveriam assumir a posição de intelectual, no sentido de criticar ou inovar o uso dos espaços nas cidades, realizando-se na emancipação e no reconhecimento da dificuldade de lidar, de um lado, com a apropriação do comum, de modo particular, e por outro lado, com o sujeito que se aliena ao modo de relacionar-se com os espaços das cidades e no encontro com o outro que se pode originar no modo inventivo que se apresenta na bricolage (AGUIAR, 1989).

A metodologia de investigação do trabalho inseriu-se primordialmente em dois elementos, que se tratam, primeiramente, numa hermenêutica da leitura de autores que subsidiam a análise sobre a questão dos espaços nas cidades e a questão da cidadania na constituição do sujeito emancipado na modernidade.

A partir dessa perspectiva teórica, buscou-se analisar e observar uma pequena singularidade da cidade: como os sujeitos se utilizam do espaço público (Figura 01). Para tanto, elegemos como recorte e fonte empírica primária uma pequena praça pública, como modo de compreender o "nãolugar" (AUGÉ, 1994) que se instaura no paradoxo do interior dos lugares das cidades. Isso de estar num lugar na cidade é que a referida praça possui endereço e lugar na cidade, mas o grande problema deste ensaio é analisar que o referido espaço no interior das cidades não possui uma representação de pertencimento de algo comum a todos. 


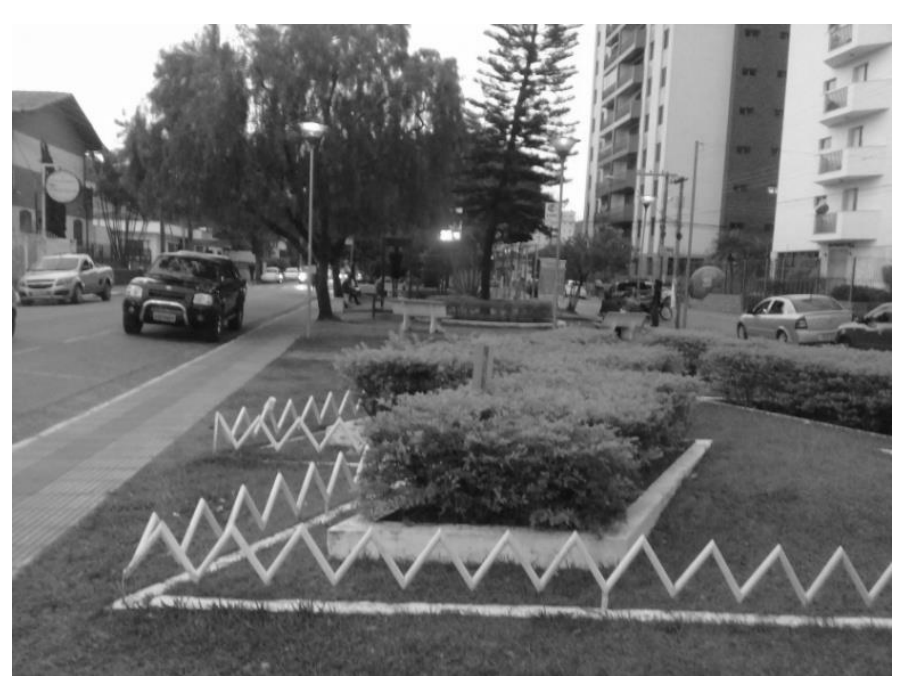

Figura 01: (Foto do autor).

Em termos físicos, o referido espaço analisado apresenta a dimensão aproximada de quinze metros de largura por noventa e cinco metros de extensão, totalizando uma área total de um mil e quatrocentos e vinte e cinco metros quadrados, em que se podem encontrar os seguintes elementos: cinco bancos de três lugares, com encosto; dez bancos de três lugares, com encosto; e dois equipamentos de espaldares, que possuem dez estações para exercício de flexão e extensão dos braços (Figura 02).

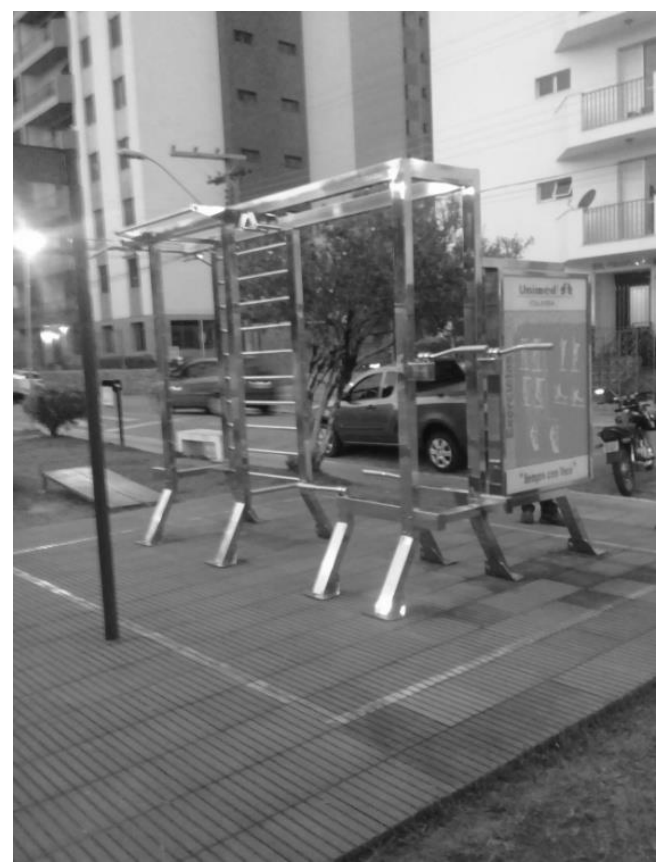

Figura 02: (Foto do autor).

Pode-se constatar, em visita ao local, que tal praça é um espaço retangular e possui todo o seu piso do entorno sinalizado para deficientes visuais, e isso se apresenta como algo inusitado, pois em toda a cidade somente esse espaço possui esse tipo de piso.

Pode-se também constatar, na visita, que a praça fica grande parte do dia completamente ociosa, e nos horários do início e final do dia, em que as 
condições climáticas são mais favoráveis, encontra-se no mínimo uma pessoa e no máximo oito pessoas.

Compreendemos que a presença desses elementos é determinante para o uso do espaço, e fica, basicamente, estabelecida a conduta de repouso nos bancos ou exercício nos espaldares. Os bancos servem ao encontro dos sujeitos que se sentam e conversam, mas são pouco utilizados durante o dia, em decorrência do desconforto térmico. Em relação aos espaldares, pode-se observar o predomínio do uso de flexão e extensão dos braços. A junção dessas duas condutas dos sujeitos perante a praça determina o uso do espaço pelos frequentadores numa área de, aproximadamente, trezentos metros quadrados.

Esse valor reduzido do uso da praça pode ser compreendido como um elemento de representação significativa, em termos simbólicos, uma vez que, numa condição de proporção da cidade, esta possui uma população de cerca de noventa e sete mil habitantes, mas que pouco requenta as áreas livres destinadas ao lazer. Essa baixa proporção no uso do espaço público se apresenta como um paradigma das cidades, que podem ser precarizados ou pouco utilizados, uma vez que se representam como os lugares que são reduzidos para a realização de atividade física e impertinentes para o encontro ou representação de pertencimento do comum a todos.

Essa condição de subordinar-se numa relação de corpo e espaço, em que se aliena para usufruir do lugar, é o elemento que determina a percepção do sujeito perante o espaço público desapropriado da coletividade e, inclusive, a referida praça é cuidada por uma empresa particular que instala a propaganda da referida marca. Isso não deixa de ser um modo de apropriação do espaço público pelo interesse particular.

Esse pequeno recorte de estudo referente à praça analisada se apresenta numa singularidade que aponta para o plural de outros diversos espaços públicos, no conceito de cidadania instrumental, em que os sujeitos se utilizam desse espaço sem interação ampla de representação deste. Nessa condição de alienação, os sujeitos não se permitem saber o nome da praça e seus diversos ornamentos, tais como estátuas ou monumentos. Isso permite compreender que a cidade se situa como lugar apenas instrumental, no sentido de perda de significado e representação da cidadania.

Partimos do pressuposto de que os lugares se encontram como não-lugar (AUGÉ, 1994) que se apresentam na contradição daquilo que é público e, simultaneamente, como algo de não pertencimento ou são utilizados como uma apropriação alienada do espaço.

Compreendemos esse conjunto de processos formativos em interface com a vida nas cidades, tendo como foco de análise as relações entre corpo e cidade mediados pelas tecnologias, na construção da percepção do sujeito perante o espaço público desapropriado da coletividade. Nessa perspectiva de análise, por um lado, as cidades se apresentam como construções tecnológicas que instituem no sujeito uma determinada representação de mundo em que "o espaço tornou-se um lugar de passagem, medido pela facilidade com que dirigimos através dele ou nos afastamos dele" (SENNETT, 1997, p. 17). 
Por outro lado, o próprio corpo também se altera nas transformações tecnológicas e passamos a constituir em outras formas de compreensão de sujeito, inclusive, numa representação híbrida entre corpo e máquina em que "[...] os modernos meios de comunicação poderiam entorpecer os sentidos" (SENNETT, 1997, p. 16). Nessa interação entre corpo e cidade mediados pelas tecnologias, torna-se evidente que somos sujeitos, que interagimos com o ritmo das máquinas que se impõe e que nos constitui como sujeitos na vida em cidade, pois

Para se tomar como um único exemplo, atravessar uma avenida expressa, especialmente em horário de rush, é um ato ousado que demanda uma sofisticada combinação de instintos, reflexos, coordenação motora e disciplina de atos concatenados. Como essa combinação complexa nos é incorporada desde cedo na vida, é muito difícil por isso atentar para quão exigente esse pequeno ritual cotidiano pode ser (SEVCENK, 1994, p. 34).

No conjunto dessas aproximações, distanciamentos e velocidades é que os sujeitos incorporam a condição da perda de sensibilidade perante a cidade sem cidadania onde habitam e se constroem, no processo formativo da percepção do sujeito perante o espaço público desapropriado da coletividade.

\section{A perda da cidadania no paradoxo das leis das cidades em oposição às leis das ruas}

Compreender a distinção entre as leis das cidades em oposição às leis das ruas significa entender por qual motivo todas as crianças e jovens deveriam estar inseridos no aparelho escolar, que inclusive se apresenta também uma referência à questão da cidadania como princípio estabelecido na Constituição Federal do Brasil em seu artigo 205:

A educação, direito de todos e dever do Estado e da família, será promovido e incentivada com a colaboração da sociedade, visando ao pleno desenvolvimento da pessoa, seu preparo para o exercício da cidadania e sua qualificação para o trabalho (BRASIL, 2018b).

Entretanto, tudo indica que prevalece uma perda de sentido do conceito de cidadania, uma vez que as cidades se encontram sem representação de algo comum a todos, em termos de pertencimento. De um lado, temos um conjunto de leis que se representam à norma estabelecida para o convívio comum e, de outro lado, temos a vida no cotidiano das ruas, em que se negligencia a completa representação das leis, e o que se prevalece é a existência de verdadeiras hordas que fazem valer seus direitos pelo uso da força bruta.

A unidade escolar se apresenta destituída como espaço de formação política, e isso se pode constatar na precária formação que atravessa as leituras das crianças e dos jovens. Para exemplificar essa questão, basta pegar os textos que estão sendo utilizados no ensino fundamental ou no ensino médio, e pode facilmente se constatar que não se encontra presente um 
conteúdo com a compreensão crítica da realidade, como por exemplo o conteúdo de história em que o mesmo esteja relacionado como

[...] acontecimento verdadeiramente importante. Em segundo lugar, há em relação a ele o recuo suficiente para evitar a alteração da percepção dos fatos pelas paixões. Em terceiro lugar, acontecimento foi tal que influenciou não só os contemporâneos, mas também as gerações seguintes, donde a variedade de atitudes a seu respeito da parte de historiadores vivendo em épocas diversas (SCHAFF, 1986, p. 10-11).

$\mathrm{Na}$ contramão do conceito de história como acontecimento, pode se observar, na nessa literatura escolar, uma narrativa restrita ao campo do narcisismo particular sobre a história. Essa pobreza teórica se apresenta como completo aniquilamento de qualquer tipo de cultura histórica ou política da vida comum nas cidades.

Esse evento anterior representa que, de um lado, prevalece a cidadania instrumental que se esvazia de representação simbólica, e de outro lado, o favorecimento para vivermos em cidades sem a representação de pertencimento ao espaço público. Esses dois lados resultam, em termos de processos formativos, na deformação do sujeito que, no âmbito da existência política nas cidades, perdem a condição de pensar criticamente sua existência como mecanismo psíquico de relacionar com o espaço a sua existência no interior das cidades - cidades sem cidadania.

Compreendemos que o ponto central de pertencimento do sujeito estaria relacionado à inserção deste nas cidades como lugar de vivência da cultura. Portanto, a partir do momento em que se apresenta postura ereta feita pelo homem, isso se apresenta como elemento de fundamental importância para a passagem e ingresso no processo civilizatório (FREUD, 1996, p. 105), que em que todo o seu entorno se constitui como possibilidade de constituir a concepção de mundo e um olhar mais crítico a uma determinada concepção de ciência, que poderia instaurar o sujeito como pertencente a seu mundo perante a coletividade daquilo que é comum a todos, em termos de história, ou de pertencimento aos espaços das cidades.

\section{Considerações finais}

A partir deste ensaio podemos concluir que temos uma necessidade de ruptura da posição de alienante para a passagem dos sujeitos na posição de intelectual, no modo de compreender coletivamente a vida nas cidades. Isso pode decorrer da existência de espaços constituídos, que podem proporcionar a experiência de existência ao sujeito em encontrar alguns pontos de fuga na constituição do sujeito alienante.

Neste caso, o maior enfretamento para essa questão, na produção de espaços de cidadania como rupturas na percepção do sujeito perante o espaço público desapropriado da coletividade, seria constituir proposições em rupturas ao modelo de cidade alienante, em que se privilegia como forma apropriada na reprodução do capital, uma vez que os sujeitos se direcionam numa relação de subordinação e disciplinamento. 
A ruptura poderá ocorrer nos espaços das cidades, no momento que se pode pensar o espaço público como lugar do comum a todos, contrapondo-se a modelos de cidades em que as técnicas e os processos formativos encontramse determinados numa hierarquia de mandar e obedecer. Portanto, dever-se-ia evitar que as relações educativas se tornem pautadas no modelo político do neoliberalismo, em que o individualismo prevalece como saída para a conquista do sucesso. Essa condição evita, inclusive, a construção da percepção do espaço público e a apropriação do particular como algo sem significado para a coletividade, o que constitui as cidades sem cidadania.

Em cada lugar, torna-se possível realizar uma proposição de ruptura, como é o caso do trabalho intitulado Mestres da obra (PUGLIESE, 2017) e o documentário Lixo Extraordinário (WALKER, 2010). No primeiro projeto, fica proposto que os operários da construção civil fazem do espaço de trabalho uma oficina de arte, aproveitando a sucata da própria construção (PUGLIESE, 2017). Já o documentário Lixo Extraordinário apresenta um trabalho de intervenção no maior aterro sanitário do mundo, em que os catadores são convidados a trabalhar com construção de outras peças a partir do lixo, o que resulta em telas de pinturas com a reapropriação da imagem de cada um. Essas telas são expostas em galerias de arte no exterior (Londres) e vendidas em leilão, e esse mecanismo ressignifica a imagem de cada sujeito e estabelece outros olhares para atividade dos catadores e do espaço de trabalho (WALKER, 2010).

Essa condição de ressignificar os lugares, mais propriamente os espaços do trabalho, permite o estabelecimento da partilha do sensível (RANCIÈRE, 2015) no campo da cultura como elemento que se encontra pautado na criatividade e, principalmente, na ludicidade, uma vez que "[...] esta metodologia está construída para funcionar dentro da realidade e a partir do funcionamento do trabalhador. Ela utiliza dos mesmos elementos do cotidiano do trabalho" (PUGLIESE, 2017, p. 75).

A partir desse outro paradigma estético de ressignificação dos espaços comum a todos é que podemos analisar a cidade como o impossível na reelaboração da percepção do sujeito perante o espaço público desapropriado da coletividade, em que o comum seria algo efetivamente pertencente a todos.

No caso da praça analisada neste estudo, o ponto de ruptura seria a possibilidade da desconstrução da cidadania instrumental para a perspectiva da cidadania participativa, em que todos os sujeitos possam se implicar com o uso do espaço público e compreender que a diversidade do que é comum a todos pode enriquecer a cada sujeito na experiência vivida nos espaços das cidades.

Nessa inversão, poder-se-ia produzir outra situação, no sentido de colocar em circulação diferentes formas de pensar sobre o uso e ocupação do espaço público e, portanto, uma reelaboração dos espaços como exercício da cidadania nas rupturas da percepção do sujeito perante o espaço público desapropriado da coletividade e, principalmente, uma esperança em destituir a posição do sujeito que se aliena perante a cidade instrumental. 


\section{REFERÊNCIAS}

AGAMBEN, Giorgio. O que resta de Auschwitz: o arquivo e a testemunha. Trad. Selvino J. Assmann. São Paulo: Boitempo, 2008.

AGUIAR, Almir de Oliveira \& SOUZA, Maria Celeste da Costa. Nota dos Tradutores da $1^{\text {a }}$ edição pela Ed. Nacional. In: LÉVI-STRAUSS, Claude. 0 pensamento selvagem. Trad. Tânia Pellegrini. Campinas: Papirus, 1989.

AUGÉ, Marc. Não-lugares: introdução a uma antrolopologia da supermodernidade. Trad. Maria Lúcia Pereira. Campinas: Papirus, 1994.

BRASIL. LEI No 9.394, DE 20 DE DEZEMBRO DE 1996. Disponível em: http://www.planalto.gov.br/ccivil_03/LEIS/L9394.htm > . Acesso em: 27 set. 2018.

BRASIL. CONSTITUIÇÃO DA REPÚBLICA FEDERATIVA DO BRASIL DE 1988. Disponível em:

http://www.planalto.gov.br/ccivil_03/constituicao/constituicaocompilado.htm. Acesso em: 9 out. 2018.

GAGNEBIA, Jeanne Marie, Apresentação. In. AGAMBEN, Giorgio. o que resta de Auschwitz: o arquivo e a testemunha. Trad. Selvino J. Assmann. São Paulo: Boitempo, 2008.

FOUCAULT, Michel Vigiar e punir: nascimento da prisão. Trad. Raquel Ramalhete. Petrópolis: Vozes, 1991.

FREUD, Sigmund. O Mal-Estar na Civilização (1930 [1929]). In: Obras Completas. v. XXI. Trad. Jayme Salomão. Rio de Janeiro: Imago, 1996.

LARROSA, Jorge. Pedagogia Profana: danças, piruetas e mascaradas. Trad. Alfredo Veiga-Neto. Belo Horizonte: Autêntica, 2004.

MENDONCA, Eneida Maria Souza. Apropriações do espaço público: alguns conceitos. Estud. pesqui. psicol., Rio de Janeiro, v. 7, n. 2, dez. 2007. Disponível em:

http://pepsic.bvsalud.org/scielo.php?script=sci_arttext\&pid=S1808$42812007000200013 \&$ Ing $=p t \& n r m=$ iso. Acessos em: 18 maio 2021.

NIETZSCHE, Friedrich Wilhelm. Humano, demasiado humano: um livro para espíritos livres. Trad. Paulo César de Souza. São Paulo: Companhia das Letras, 2000.

PUGLIESE, Arthur Zobaran et al. Mestre da Obra. São Paulo: Ministério da Cultura \& Itaú, 2017. 
RANCIÈRE, Jacques. A partilha do sensível: estética e política. São Paulo: Editora 34, 2015.

SENNETT, Richard. Carne e Pedra: o corpo e a cidade na civilização ocidental. Trad. Marcos Arão Reis. Rio de Janeiro: Record, 1997.

SENNETT, Richard. O declínio do homem público: as tiranias da intimidade. Trad. Lygia Araujo Watanabe. São Paulo: Companhia das Letras, 1995.

SEVCENK, Nicolau. Futebol, metrópoles e desatinos. Revista da USP: dossiê futebol. São Paulo, n. ${ }^{2} 22$, p. 30-37, jun./jul./ago. 1994.

SCHAFF, Adam. História e Verdade. Trad. Maria Paula Duarte. São Paulo: Martins Fontes, 1986.

TUAN, Yi-Fu. Topofilia: um estudo da percepção, atitudes e valores do meio ambiente. Trad. Lívia de Oliveira. São Paulo: DIFEL, 1980.

WALKER, Lucy. Lixo Extraordinário. Brasil: Hank Levine e Angus Aynsley. 2010. 90 minutos.

Recebido em: 4 de fevereiro de 2021. Aceito em: 20 de maio de 2021. Publicado em: 15 de dezembro de 2021.

i Agradecimento à Universidade Federal de Itajubá (UNIFEI) e aos alunos que, durante a pandemia, se mantiveram dedicados aos estudos. 